\title{
ENTRE DIVERSIDADE PROFUNDA E PATRIOTISMO CONSTITUCIONAL: O DIÁlOGO ENTRE HABERMAS E TAYLOR
}

Maria Eugenia Bunchaft*

\begin{abstract}
Resumo
$\mathrm{Na}$ discussão sobre o multiculturalismo, teóricos políticos criticam a concepção liberal de cidadania. Nesse sentido, destaca-se a perspectiva teórica de Charles Taylor, que desenvolveu uma política da diferença capaz de atender às pretensões de grupos historicamente discriminados. Jürgen Habermas, por sua vez, foi um dos mais brilhantes filósofos da segunda geração da Escola de Frankfurt, delineou uma perspectiva procedimentalista acerca da filosofia política do reconhecimento que se contrapõe de forma marcante à perspectiva filosófica desenvolvida por Charles Taylor, tendo em vista o seu modelo de self pós-convencional. Esse artigo procura esclarecer o debate por meio da contraposição teórica entre a idéia de diversidade profunda delineada por Taylor e a concepção de patriotismo constitucional desenvolvida por Jürgen Habermas. Defendo a tese segundo a qual o modelo de patriotismo constitucional constitui um modelo sofisticado de integração da diferença capaz de atender aos desafios de sociedades multiculturais.
\end{abstract}

Palavras-chave: Taylor. Habermas. Multiculturalismo. Patriotismo constitucional. Reconhecimento.

\section{Introdução}

Charles Taylor (2000) desenvolveu uma filosofia do reconhecimento cujo objetivo central é a reflexão sobre as pretensões de grupos minoritários conectada a uma política da diferença, tendo em vista o caráter essencialmente dialógico da natureza humana. $\mathrm{O}$ filósofo também desempenhou um importante papel político no Canadá, onde ocupou o cargo de vice-presidente do New Democratic Party, sendo que sua atuação política, voltada para a proteção da minoria francófona em seu país, se refletiu profundamente em sua filosofia do reconhecimento, enfatizando a centralidade da proteção de bens culturais que assegurem a preservação de

* Professora do Programa de Pós-graduação em Direito da UNISINOS. Doutora e Mestre em Direito pela PUC-Rio. Pós-Doutoranda em Filosofia pela UFSC. Autora do livro "O patriotismo constitucional na perspectiva de Jürgen Habermas", ed. Lumen Juris, 2010. mbunchaft@ig.com.br. 
identidades minoritárias. Nesse aspecto, Taylor (2000) salienta que a perspectiva intersubjetiva de construção da identidade é um elemento incontornável do ser humano, destacando que formas opressivas de dominação sobre grupos minoritários trazem reflexos negativos sobre a autoestima, pois implicam processos distorcidos de reconhecimento mútuo e expressão de desigualdades.

É premente frisar que Taylor (2000), ao analisar o contexto canadense, se contrapõe a políticas universalistas, propugnando uma política da diferença, considerada pelo autor como uma reação ao liberalismo insensível às identidades minoritárias. Em síntese, a proposta assumida pelo filósofo canadense baseia-se no ideal da diversidade profunda em defesa do reconhecimento da distintividade cultural quebequense, ainda que impondo limitações a direitos individuais. Mas será que a política da diferença, delineada por Taylor, não conduz a essencializações identitárias? Existe uma relação necessária entre ideal da autenticidade e política da diferença? Nesse sentido, a polêmica com Jürgen Habermas (2002a) é inevitável.

Habermas (2002a) delineou uma perspectiva procedimentalista acerca da filosofia política do reconhecimento que se contrapõe de forma marcante à filosofia do reconhecimento desenvolvida por Charles Taylor (2000), tendo em vista o seu modelo de self pós-convencional. Por um lado, para Habermas (2002a), o sistema de direitos possui uma sensibilidade inclusiva em relação às diferenças culturais, de forma que grupos e minorias devem articular em processos discursivos aquelas tradições que propugnam manter ou questionar. De outro lado, Habermas (1994), por meio do seu conceito de patriotismo constitucional, desenvolveu uma concepção original de identidade política, que se opõe ao modelo de política da diferença esboçado por Taylor (2000). Pretendemos nesse trabalho apresentar um debate entre os referidos autores, no que se refere à contraposição teórica do modelo de self autointerpretativo delineado por Taylor (1985) e self pósconvencional esboçado por Habermas (2012), ou ainda, entre diversidade profunda e patriotismo constitucional. 


\section{A filosofia de Charles Taylor}

Charles Taylor (2000) compreende o reconhecimento como uma questão de autorrealização, estando atento à necessidade de enfatizar a prioridade de proteção de bens culturais que assegurem a preservação de identidades minoritárias. Ao salientar a dimensão psicológica do reconhecimento, destaca que a recusa do reconhecimento tem reflexos sobre a autoestima e suscita a internalização de imagens autodepreciatórias. Daí a sua defesa do caráter dialógico da natureza humana, pois o indivíduo só se autodefine na relação com a alteridade social, estabelecendo a relação entre a necessidade de reconhecimento e sua vinculação com a identidade:

(...) a tese é de que nossa identidade é moldada pelo reconhecimento ou por sua ausência, freqüentemente pelo reconhecimento errôneo por parte dos outros, de modo que uma pessoa ou um grupo de pessoas podem sofrer reais danos, uma real distorção, se as pessoas ou sociedades ao redor deles lhes desenvolverem um quadro de si mesmas redutor, desmerecedor ou desprezivel. (TAYLOR, 2000, p. 241)

Nesse quadro teórico, o pressuposto de Taylor (2000) constitui a não neutralidade das ações, porquanto uma abordagem cientificista termina por desincorporar o self de um horizonte valorativo, e não considera que a nossa subjetividade seja nutrida por configurações morais. Se a esfera moral, na perspectiva tayloriana, não pode ser abordada sob um enfoque universalista - pois envolve a possibilidade que o ser humano tem de realizar avaliações fortes que determinam o próprio sentido de sua existência assume especial relevância a sua crítica a filosofias universalistas, tal como a filosofia kantiana, que desconsideram a conexão intrínseca entre o self $e$ o bem. ${ }^{1}$

Nessa linha de raciocínio, Taylor (1985) considera profundamente a capacidade que o ser humano possui de se autointerpretar, posicionando-se sobre questões que afligem a vida comunitária e que são essenciais a uma vida plena; daí a importância de o agente tomar consciência dos fundamentos valorativos que nutrem suas ações, pois esses são 
determinantes para o sentido de uma vida digna. Nem todas as escolhas cotidianas implicam distinções qualitativas, pois existem escolhas triviais que não determinam tão profundamente a construção de nossa identidade; mas há determinadas escolhas que são essenciais à construção de uma concepção de dignidade e que implicam discriminações valorativas a serem realizadas por um processo autointerpretativo. Nesse particular, Taylor (2000) apresenta-nos a sua filosofia do reconhecimento.

\section{A politica de reconhecimento}

É mister explicitar que a ideia fundamental da filosofia tayloriana é a de que somos seres autointerpretativos, que construímos nossa identidade imersos em uma comunidade cultural com a qual nos relacionamos linguisticamente, sendo que, por meio de relações dialógicas, em redes de tradições compartilhadas, alcançamos uma compreensão plena a respeito de nossas singularidades. (TAYLOR, 1985). Assim, autointerpretação e avaliação forte não se realizam em uma perspectiva monológica, mas em dimensão essencialmente dialógica que permite ao indivíduo articular com profundidade o conteúdo de seu universo moral. É esse pano de fundo que fornece significado à nossa existência. Com efeito, o aspecto dialógico da identidade humana torna fundamental uma política da diferença, porque o universalismo do direito à igualdade e à dignidade não deve anular a unicidade, a autenticidade e a originalidade de cada indivíduo. Destaca que grupos historicamente discriminados precisam se libertar de uma identidade imposta e destrutiva, o que exige uma política da diferença, uma vez que a depreciação sistemática possui efeitos negativos em relação à autoestima.

Portanto, o conceito de dignidade igual surge nas sociedades prédemocráticas como reflexo de uma política universalista, isto é, a dignidade igualitária passa a ser encarada como um valor comum a todos os indivíduos, substituindo o conceito de honra, que estava vinculado a hierarquias sociais. O ideal da dignidade igualitária surge a partir de uma política universalista de reconhecimento da dignidade igual dos cidadãos e da igualdade de direitos vinculada tradicionalmente à exclusão da 
discriminação e, portanto, da diferença. A partir desse momento, Taylor (2000) introduz a noção de identidade como autenticidade - uma identidade peculiar que revela uma essência autêntica, ou seja, uma forma original de ser humano. O ideal da autenticidade surge no final do século XVIII, a partir da visão da autorrealização centrada que se vincula não a uma entidade superior, mas a uma fidelidade a si mesmo. Nesse aspecto, Herder é um interlocutor privilegiado para Taylor (2000), apresentando a ideia de que cada um de nós tem um modo original de ser humano, o que implica na necessidade de resgatarmos nossa essência autêntica.

Em face dessa percepção filosófica, o liberalismo clássico estaria relacionado com a primeira dimensão, mas permaneceria fechado em relação ao ideal da autenticidade. Taylor (2000) associa a política da dignidade igual com a leitura particular do liberalismo (procedimental), de acordo com a qual o Estado garantiria direitos e liberdades individuais, devendo ser neutro em relação às visões substantivas individuais e coletivas, ou seja, seria inteiramente cego em relação às diferenças dos cidadãos. A política da diferença, vinculada ao ideal da autenticidade, pressupõe que cada indivíduo teria uma expressão singular e original que deveria ser reconhecida pela sociedade.

Nessa trajetória teórica, o filósofo, analisando o caso canadense, propõe a instituição de medidas normativas que visam a resguardar os direitos da minoria francófona no Canadá, defendendo um liberalismo sensivel às identidades culturais. Para Taylor (2000), enquanto o liberalismo 1 está voltado para a garantia dos direitos e liberdades individuais, o liberalismo 2 seria um modelo de sociedade liberal sensível às singularidades culturais específicas, tendo em vista a experiência de seu próprio país, o Canadá. O reconhecimento de Quebec como uma sociedade distinta, na emenda Meech à Carta Canadense de Direitos de 1982, deu lugar a uma série de normas restritivas que violam direitos individuais em nome do objetivo da sobrevivência da cultura francófona no Canadá. Taylor (2000) considera possivel um outro modelo de sociedade liberal, sendo necessárias políticas públicas que contemplem a proteção às diferenças culturais.

Não obstante, a perspectiva tayloriana foi objeto de críticas pela 
filosofia procedimental habermasiana, que se contrapõe a essencializações identitárias. Nesse tópico, passamos a analisar a crítica de Habermas (2002a).

\section{A critica habermasiana}

Jürgen Habermas (2002a) delineou uma perspectiva original sobre o reconhecimento nas sociedades multiculturais, tendo em vista uma compreensão procedimental. Na perspectiva de Habermas (2002a), as identidades culturais devem ter a prerrogativa de questionar tradições e práticas culturais existentes, podendo inclusive distanciar-se reflexivamente das mesmas. A preservação de certos direitos culturais que impliquem restrições à autonomia individual, não se compatibilizam com a construção de uma cultura política aberta e universalista. Nesse aspecto, situa-se a crítica de Habermas (2002a) à perspectiva tayloriana, alegando que não deveríamos preservar as culturas da mesma forma que as espécies.

Em face desta leitura, para Habermas (2002a), o universalismo dos direitos humanos possui uma sensibilidade inclusiva em relação às diferenças culturais, de forma que Taylor (2000), ao defender a restrição de direitos individuais em favor de direitos culturais, ignora que os destinatários das normas só alcançam autonomia à medida que se compreendem como autores e destinatários dos seus direitos. De um lado, entendemos que tais concepções de vida digna não podem ser impostas de forma paternalista, porquanto devem ser discutidas racionalmente mediante trocas de argumentos; de outro lado, os indivíduos não deixam de se identificar com seus desejos e projetos singulares, mas passam a compreendê-los em uma perspectiva mais abrangente que pode implicar, até mesmo, um certo distanciamento reflexivo em relação a suas tradições.

Nesse cenário, a cidadania perdeu o sentido de pertencimento a uma comunidade cultural, e a herança republicana só pode ser salva à medida que os cidadãos participam ativamente do processo político e se identificam com um projeto constitucional compartilhado, assumindo especial relevância o conceito de patriotismo constitucional. 


\section{O conceito de patriotismo constitucional}

O tema do patriotismo constitucional emergiu no contexto da reconstrução da identidade alemã. O Historikerstreit consistiu no embate teórico na República Federal da Alemanha, no qual intelectuais alemães discutiram o significado histórico do Holocausto. Foi Jürgen Habermas (1994) que, durante a metade da década de oitenta, se contrapôs ao neohistoricismo e sua tentativa de minimizar as tragédias do Holocausto. $\mathrm{O}$ filósofo assumiu uma postura crítica em relação às interpretações revisionistas que minimizavam o sentido do holocausto e das atrocidades cometidas no nazismo. ${ }^{2}$ Assim, o patriotismo constitucional alemão inspirou um processo de reconstrução da identidade alemã que, superando o nazismo, estabeleceu uma estrutura normativa baseada no Estado de direito, nos direitos fundamentais e nos valores de uma cultura política liberal. (HABERMAS, 1998b, p. 115-116). O autor alemão desenvolveu o conceito de patriotismo constitucional ao delinear um modelo de identificação política capaz de superar uma identidade etnocultural. ${ }^{3} \mathrm{O}$ patriotismo constitucional não se baseia em características etnoculturais, mas nas práticas argumentativas de adesão a um projeto constitucional democrático.

É precisamente nesse sentido, que se situa a crítica de Habermas (2002a) à abordagem comunitarista proposta por Charles Taylor (2000), no que se refere à proteção das identidades culturais. ${ }^{4}$ Entende que a perspectiva ecológica de preservação das espécies não pode ser transposta para o plano cultural. De fato, os legados culturais não podem ser impostos, pois os membros dos grupos culturais devem ser livres para questionar tradições culturais, tendo em vista o potencial crítico das identidades. ${ }^{5}$ Como a concepção de moralidade pós-convencional, em Habermas(2002a), é compativel com a ideia de que as democracias contemporâneas podem se organizar em torno de valores centrais, o patriotismo constitucional deve se ancorar em uma concepção de cidadania democrática capaz de gerar uma solidariedade entre estranhos, ou seja, entre indivíduos de culturas diversas. Defensores do patriotismo constitucional - como Justine Lacroix (2002), 
Omid Payrow Shabani (2002) e Ciaran Cronin (2003) - têm argumentado que o conceito é capaz de acomodar diferenças e pluralidades desde que os cidadãos estejam socializados em uma cultura política comum de valores democráticos liberais.

Antes de tudo, é mister frisar que uma identidade coletiva, fundamentada em um projeto constitucional compartilhado, pode conquistar a lealdade dos membros dos diversos subgrupos religiosos e culturais, dentro de uma cultura política comum que transcenda suas diferenças. De acordo com Habermas (2002a), por meio de processos de deliberação discursiva, os cidadãos dos Estados democráticos reconhecem a si próprios, simultaneamente, como autores e destinatários dos princípios constitucionais, inspirando um sentimento de solidariedade entre indivíduos de diversos backgrounds.

Nesse quadro teórico, Ciaran Cronin (2003), professor de Filosofia na University of Illinois, e um dos mais ilustres defensores do empreendimento habermasiano, por sua vez, destaca: "os indivíduos não deixam de se identificar com seus desejos e projetos, mas passam a compreendê-los em uma perspectiva abrangente que lhes permite refletir criticamente sobre suas uniões e compromissos, sem ter que negar quem são” (CRONIN, 2003, p. 4). Nesse sentido, em face do exercício crítico da razão, as próprias concepções de bem passam a ser discutidas racionalmente, motivo por que compreendemos que a lealdade aos princípios constitucionais e às instituições políticas por eles estruturadas pode gerar uma cultura política independentemente de uma concepção etnocultural de cidadania. Partindo de uma perspectiva habermasiana, percebemos que Taylor (2000) pressupõe apenas a moralidade convencional, desconsiderando o exercício crítico da razão. Compartilhamos com a perspectiva habermasiana a ideia de que, na sociedade pós-convencional canadense, o ideal do patriotismo constitucional pode guiar a negociação política dos anglófonos, francófonos, povos nativos e criar um regime justo de associação política. Analisando o tema, Omid Payrow Shabani (2002), professor de Filosofia da University of Guelph, e um dos maiores defensores da concepção habermasiana de patriotismo constitucional, ressalta que: 
(...) portanto, embora exista um contexto histórico que embase a identidade política canadense, a diversidade e a maturidade de desenvolvimento de suas forças políticas tornam-nos capazes e exigem-nos que superemos critérios particularistas de associação em favor de um critério universal baseado em direitos. (SHABANI, 2002, p. 438).

Nessa linha de raciocínio, Taylor (2000), ao contrapor-se a um suposto processo de assimilação das políticas de dignidade igual, pressupõe apenas a moralidade convencional na sua política de reconhecimento, como se a nossa subjetividade fosse determinada de forma absoluta e exclusiva por uma comunidade linguística. Embora também pressuponha o caráter dialógico da natureza humana, a perspectiva habermasiana é capaz de transcender reflexivamente os limites de uma comunidade cultural específica com base no exercício crítico da razão. Em vista disso, o herdeiro da Escola de Frankfurt procura resgatar os pressupostos pragmáticos da comunicação, por meio dos quais os indivíduos negociam pretensões de validade, de forma a transformar suas relações com o mundo. ${ }^{6}$ Em sintese, o debate possui um potencial racionalizador na construção de liames identitários inseridos em uma cultura política aberta e inclusiva.

Disso se infere, ao nosso ver, a importância da compreensão habermasiana, que estimula o exercício crítico da razão por meio de um certo distanciamento reflexivo em relação a nossas contingências culturais e históricas. Analisando a perspectiva habermasiana, Justine Lacroix, professora da Université Libre de Bruxelles, salienta que "um dos objetivos do patriotismo constitucional é promover uma cultura política compartilhada (e não única). Ao invés de negar a importância das peculiaridades nacionais, essa cultura política deveria emergir do processo de confrontação e deliberação aberta entre as várias culturas nacionais...” (LACROIX, 2002, p. 951). Antes de Direito e Democracia, porém, o poder emancipatório da razão comunicativa, delineada por Habermas (2012) em Teoria do Agir Comunicativo, havia sido objeto de críticas de feministas como Nancy Fraser (2000), pois não era capaz de se contrapor a uma ideologia de gênero opressora, que marcava o mundo da vida. 
Desse modo, Fraser (2000), uma das principais teóricas feministas do reconhecimento, constatou que a teoria habermasiana da ação comunicativa não tinha potencialidade para acomodar alguns dos insights do feminismo moderno e superar a concepção androcêntrica de mundo. As consequências patológicas da penetração dos imperativos sistêmico nas dinâmicas do mundo da vida e nas estruturas familiares produziam uma ideologia de gênero extremamente opressora. Marie Fleming (1997) observou que Habermas não reconhecia explicitamente se as estruturas familiares do mundo da vida seriam organizadas por relações de dominação e subordinação. O filósofo não esclarecia se a racionalidade comunicativa poderia impor limites aos imperativos estratégicos ou se seria suprimida pelos imperativos sistêmicos, razão por que muitas feministas consideravam a teoria habermasiana incapaz de contemplar as circunstâncias e necessidades específicas do feminismo, tendo em vista a separação analítica entre os domínios público e privado.

Entretanto, em Direito e Democracia, Habermas (2003b) estabelece a cooriginariedade entre autonomia pública e privada, distanciando-se da tradição liberal, respondendo às críticas feministas de forma coerente. Habermas (2003b) não mais afirma a neutralidade ética do Estado Constitucional, mas destaca que discursos éticos passam a permear os processos de deliberação discursiva. O reconhecimento da impregnação ética do Estado Constitucional - como um fato inerente ao processo democrático constituiu um esforço teórico essencial para flexibilizar sua distinção rígida entre questões éticas e morais, em resposta a perspectivas críticas, como a de Taylor (2000), no sentido de que o liberalismo seria inteiramente cego às diferenças. As pessoas que constroem uma nação de cidadãos estão inseridas em uma rede de tradições e contextos intersubjetivamente compartilhados de experiências de vida; portanto, qualquer sistema legal é expressão de uma forma de vida particular e não meramente reflexo de características universalistas consubstanciadas em direitos básicos. Por esta razão, os princípios constitucionais devem ser interpretados a partir do ponto de vista das singularidades culturais específicas, interpretação esta que não pode ser eticamente neutra (HABERMAS, 2002a). 
Em face dessa concepção filosófica, para Habermas (2002a), o sistema de direitos não é cego em relação às diferenças culturais, procurando desenvolver uma perspectiva procedimental com fulcro na concepção de cooriginariedade entre autonomia pública e privada. Sem direitos fundamentais não haveria como estabelecer as condições procedimentais necessárias ao exercício da autonomia pública; mas, sem o exercício de sua autonomia pública, os cidadãos não são capazes de articular discursivamente suas concepções de bem:

Os cidadãos só podem fazer um uso adequado de sua autonomia pública quando são independentes o bastante, em razão de uma autonomia privada que esteja equanimemente assegurada; mas também o fato de que só poderão chegar a uma regulamentação capaz de gerar consenso, se fizerem o uso adequado de sua autonomia política enquanto cidadãos. (HABERMAS, 2002a, p. 293)

Com efeito, a autonomia pública e a privada pressupõem-se mutuamente e, nesse sentido, Habermas contrapõe-se à perspectiva tayloriana, destacando que a restrição a direitos individuais, para garantir bens culturais, assume uma perspectiva paternalista que mina a sua articulação em processos discursivos. ${ }^{7} \mathrm{O}$ filósofo canadense tenderia a minimizar que os cidadãos só obtêm autonomia "quando se compreendem como autores e destinatários dos seus direitos" (HABERMAS, 2002a, p. 234). $\mathrm{O}$ autor alemão leciona que os mundos culturais possuem um caráter dinâmico que só se manifesta por meio do diálogo entre os liames identitários, não havendo razão para essencializar tais identidades como realidades isoladas. O filósofo, em passagem elucidativa, sublinha que:

Em sociedades multiculturais, a coexistência eqüitativa das formas de vida significa para cada cidadão uma chance segura de crescer sem perturbações em seu universo cultural de origem, e de também poder criar seus filhos nesse mesmo universo; ou seja, significa a chance de poder confrontar-se com sua cultura de origem - como com qualquer outra - dar-lhe continuidade ou transformá-la, ou ainda a chance de distanciar-se com indiferença de seus imperativos, ou mesmo romper com ela, em uma atitude autocrítica, para viver a partir daí com a marca deixada por uma ruptura consciente. As 
culturas só sobrevivem se tiram da crítica e da cisão a força para uma auto-transformação. Garantias jurídicas só podem se apoiar sobre o fato de que cada indivíduo, em seu meio natural, detém a possibilidade de regenerar essa força. E essa força, por sua vez, não nasce apenas do isolamento em face do estrangeiro e de pessoas estrangeiras, mas nasce também - e pelo menos em igual medida - do intercâmbio com eles. (HABERMAS, 2002a, p. 252).

Nessa empreitada teórica, Habermas (2002a) propugna uma ética do discurso conectada às demandas por reconhecimento por meio de uma Constituição que promove uma sensibilidade inclusiva em relação às diferenças culturais. A cultura política comum deve ter um potencial de integração entre liames identitários, minimizando o risco da fragmentação. Analisando a perspectiva habermasiana, Andrea Baumeister (2003), professora da University of Stirling, na Escócia, destaca que as concepções relativas à cooriginariedade entre as autonomias pública e privada e à impregnação ética do Estado permitem "uma concepção complexa e sofisticada sobre a distinção público/privado e o relacionamento entre o justo e o bem. Isso assegura que sua perspectiva seja realmente sensível àquelas preocupações expressas pelos advogados do multiculturalismo”. (BAUMEISTER, 2003, p. 746).

Indubitavelmente, para Habermas (2002a), a centralidade da impregnação ética do Estado Constitucional permite um ideal universalista sensivel à diferença, porquanto tanto questões morais como questões éticas podem ser discutidas racionalmente. Se todo Estado é eticamente impregnado e interpreta princípios constitucionais à luz de experiências históricas particulares, a cultura política deve refletir uma multiplicidade de autocompreensões éticas, e não deve favorecer nem discriminar subculturas específicas. De um lado, a cultura política comum - que reflete o processo de confrontação e deliberação entre a multiplicidade de liames identitários deve permanecer forte o suficiente para resguardar a nação de cidadãos do risco da fragmentação.

De outro lado, uma vez que a autonomia pessoal só pode ser protegida se também for protegido o contexto de vida no qual a identidade é 
formada, é importante que as necessidades específicas e as aspirações associadas com o contexto de vida particular sejam claramente compreendidas. É fundamental que grupos historicamente discriminados possam se inserir em debates públicos e práticas democráticas que lhe propiciem uma real percepção sobre seus interesses, sob pena de adotarmos uma perspectiva paternalista que restringe direitos individuais para proteção de bens culturais.

Em suma, as identidades possuem um potencial crítico que somente se expressa por meio do diálogo com a alteridade social. Para Taylor (1985), o self é um projeto, suscetivel a transformações por meio de autointerpretações, porquanto cada vez que o indivíduo articula linguisticamente seus sentimentos, inaugura-se uma nova configuração moral que transforma o seu universo substantivo. Nesse sentido, Taylor apresenta-nos a idéia de um self auto-interpretativo.

\section{Self Autointerpretativo versus self pós-convencional}

De início, Taylor (1985) sublinha que um elemento peculiar dos seres racionais é realizar avaliações fortes como uma forma de atenuar certos antagonismos morais e contradições sobre a vida boa, sendo que essa possibilidade singular de estabelecer distinções qualitativas entre os bens e critérios - que distinguem o justo do injusto, o nobre do vulgar - marca o apaixonante universo humano. As avaliações fortes são questionamentos inescapáveis à subjetividade humana e a uma vida plenamente realizada em oposição a uma existência moralmente irrelevante - pois tais discriminações qualitativas conferem significado a uma existência realmente autêntica. Ressaltamos que a compreensão tayloriana de avaliações fortes tem como fonte de inspiração a ideia de desejos de segundo grau, esboçada por Harry Frankfurt: desejos incidentes sobre nossos próprios desejos. (TAYLOR, 1985). A capacidade de valorar determinados desejos intrínsecos à nossa realização pessoal constitui um traço distintivo do ser humano.

Tal perspectiva decorre do fato de que nossa identidade, nossos desejos e projetos de vida estão conectados a uma configuração moral 
singular que se expressa pelas avaliações fortes, sendo estas um fato incontornável de uma vida digna. Saber quem somos implica saber quais são nossas alternativas morais, porque em tal universo substantivo existem bens valiosos que nos permitem assumir posições peculiares ao definir o próprio sentido de nossa vida. De um lado, o ato de posicionar-se diante de uma configuração moral possui uma dimensão constitutiva em relação à condição humana, porquanto por meio das suas fontes valorativas, o agente orientase na sua existência.

De outro lado, não obstante o adjetivo "forte" para qualificar a avaliação, Taylor (1985) refere-se à qualidade da avaliação, e não à intensidade de desejos tais como ódio, ciúme, vingança, sendo assim caracterizada por contemplar um conteúdo valorativo e constitutivo da nossa subjetividade, de forma que, eventualmente, o agente poderá ser capaz de superar tais sentimentos, tendo em vista valores mais singelos, como, por exemplo, a possibilidade de perdão.

Para Taylor (1985), a concepção segundo a qual o indivíduo compreende sua vida em termos de uma narrativa pressupõe uma pluralidade de bens que constituem seu universo moral. Nesse sentido, o agente procura posicionar-se em face de uma pluralidade de bens, elegendo aqueles que lhes são mais caros. A fim de determinar o papel estabelecido pelos diferentes bens e sua relevância emotiva, o sujeito procura articulá-los, explicitando as concepções de bem que irão determinar suas escolhas morais. Segundo Taylor (1985), em face de uma multiplicidade de bens que integram nossas configurações morais, a capacidade que o ser humano possui de se autointerpretar relaciona-se com sua busca incessante pela realização pessoal. A ideia fundamental do self-interpreting animal é a de que nossas ações são moldadas pela articulação simbólica de nossos sentimentos, que servem de norte para determinadas opções valorativas, porque a avaliação- forte não implica necessariamente uma articulação consciente das nossas fontes morais, sendo possível realizarmos distinções qualitativas na esfera de uma moralidade inarticulada. Tais bens, fortemente avaliados, podem condicionar nossas opções e escolhas, ainda que de forma inconsciente ou desarticulada. 
Em face dessa concepção teórica, é a linguagem que permite a articulação simbólica dos nossos sentimentos, de forma a organizar os nossos desejos aparentemente desarticulados, sendo que a avaliação forte, por meio da articulação linguística, permite compreender mais profundamente e estruturar nossos sentimentos, de forma a estabelecer distinções qualitativas entre os bens. Em síntese, é articulando esses dois elementos teóricos - interpretação e sentimento - que Taylor (1985) delineia a possibilidade de estabelecer avaliações-fortes como um aspecto incontornável do agente humano, constituindo o substrato emotivo necessário para que o agente resgate suas fontes morais. Alguns desejos alcançam dimensão qualitativa diversa, razão por que assume especial relevância o processo de articulação linguística, que torna mais claro para o agente o verdadeiro sentido emocional de suas ações morais.

É necessário elucidar, todavia, que a articulação não ocorre em uma perspectiva instrumental relativa à designação dos objetos, mas busca revelar os bens presentes em um universo cultural. Diferentemente de Habermas (2002a), portanto, a concepção de racionalidade tayloriana é substantiva: os bens e valores articulados pelo sujeito relacionam-se às práticas culturais de uma comunidade, porquanto o desvelamento dos mesmos pressupõe um processo autointerpretativo no qual o sujeito se compreende como membro de uma comunidade linguística. Em Habermas(2002a), diferentemente, é possível um distanciamento reflexivo em relação aos padrões culturais de uma sociedade.

Esse aspecto é particularmente interessante, pois trata-se de uma teoria da evolução moral desenvolvida por Habermas (2003a), a partir das pesquisas de Jean Piaget e Lawrence Kohlberg, compreendendo a ontogênese da personalidade humana por meio de três dimensões: a estruturação da capacidade cognitiva, da capacidade linguística e da capacidade interativa. Kohlberg estabelece uma sucessão de seis estágios subdivididos em três níveis de desenvolvimento da competência moral dos indivíduos - préconvencional, convencional e pós-convencional. Os seis estágios descritos por Habermas com base em Kohlberg são os seguintes: orientação para a punição e a obediência; orientação ingênua e egoísta; orientação para o ideal 
do bom menino; orientação para a preservação da autoridade e da ordem social; orientação legalista-contratual; orientação por princípios.

No primeiro estágio moral do nível convencional, a criança move-se pela obediência literal às regras e à autoridade, evitando o castigo e o poder superior das autoridades. No segundo estágio, as regras são cumpridas quando forem necessárias à satisfação dos interesses e necessidades próprias. A criança responde às noções de certo e errado compreendidas em uma perspectiva egocêntrica, sempre visando, instrumentalmente, às próprias necessidades, em termos de recompensas. (HABERMAS, 2003a, p. 152). Habermas (2003a) estabelece uma homologia entre esse nível de desenvolvimento moral e a identidade coletiva das sociedades tribais, nas quais o direito ainda não é um direito cogente. Os pecados e crimes são julgados sob o ponto de vista "da compensação de um prejuízo causado; só são moralmente relevantes as consequências da ação, não as intenções dos réus.” (HABERMAS, 2012, p. 318). Assim, por exemplo, a violação do tabu do incesto é considerada como uma transgressão à ordem sagrada cujas consequências ameaçam a coletividade. A validade das normas decorre de ações rituais de uma comunidade e não por sanções externas monopolizadas pelo Estado.

O nível convencional compreende o terceiro estágio moral (das expectativas interpessoais mútuas, dos relacionamentos e da conformidade) e o quarto estágio (da preservação do sistema social e da consciência). No terceiro estágio, o indivíduo preocupa- se com as demais pessoas e seus sentimentos, mantendo-se leal e digno de confiança, sendo motivado a seguir as regras e expectativas. No quarto estágio, o indivíduo preocupa-se em "manter em funcionamento a instituição como um todo, o auto-respeito ou a consciência compreendida como o cumprimento das obrigações definidas para si próprio ou a consideração das consequências.” (HABERMAS, 2003a, p. 153).

No nível moral convencional, por sua vez, a criança respeita a regra e procura atender a padrões sociais legítimos determinados pelas expectativas familiares ou sociais, desconsiderando as consequências imediatas de suas ações, mas, tendo em vista, um sentido de engajamento 
relativamente ao meio social no qual se insere. Nas palavras de Habermas, no nível convencional, "a criança incorpora as universalidade simbólicas dos papéis menos fundamentais de seu ambiente familiar e, mais tarde, as normas de ação de grupos mais amplos, a identidade natural acoplada ao seu organismo é substituída por uma identidade constituída por papéis e mediatizada simbolicamente." (HABERMAS, 1990, p. 79).

Habermas (2012) estabelece uma homologia entre esse nivel de desenvolvimento da consciência moral e a identidade coletiva de sociedades convencionais, que são aquelas sociedades organizadas na forma de Estado e nas quais a autoridade política estabelece meios de sanção centralizados que atribuem efeitos vinculantes às decisões dos que ocupam cargos. Nas palavras de Habermas, "A autoridade do soberano não decorre de algo meramente fático, e sim de um poder de sanção reconhecido como legítimo pelos membros do direito." (HABERMAS, 2012, p. 319). O crime, por exemplo, é considerado uma violação por um indivíduo a normas reconhecidas intersubjetivamente. A violação à norma é medida pela intenção do agente que age responsavelmente e o castigo não se destina à compensação dos efeitos negativos da ação, mas a um agir culposo.

A superação da identidade convencional ocorre na adolescência, "quando o jovem aprende a importante diferença que existe entre as normas, por um lado, e, por outro, os princípios segundo os quais podemos produzir normas.” E conclui: “Tais princípios podem servir como critério para a crítica e a justificação de normas preexistentes. Aliás, para quem julga segundo princípios, todas as normas vigentes só podem aparecer como posições, como meras convenções." (HABERMAS, 1990, p. 80). O nível pósconvencional inclui o estágio dos direitos originários ou do contrato social ou da utilidade (quinto estágio) e o estágio de princípios éticos universais (sexto estágio). No quinto estágio, o indivíduo sustenta direitos, valores e contratos legais básicos, "mesmo quando entram em conflito com as regras e leis concretas do grupo." (HABERMAS, 2003, p. 153). Os indivíduos se conscientizam de que a sociedade é composta por uma pluralidade de valores e opiniões, sendo que a maioria dos valores e regras são relativos a seus grupos. E concluiu: “alguns valores e direitos não-relativos, tais como a 
vida e a liberdade, têm que ser apoiados em qualquer sociedade independentemente da opinião da maioria." (HABERMAS, 2003, p. 154). Por fim, no sexto estágio, o indivíduo adere a princípios éticos universais, que tornam-se o fundamento de validade das leis e acordos sociais particulares. As leis e acordos sociais particulares são válidos porque não violam princípios universais de justiça.

Nas sociedades pós-convencionais, o direito, além de contemplar a dimensão da positividade, requer a necessidade de justificação. Para Habermas, "o sistema jurídico como um todo necessita de uma ancoragem em instituições básicas capazes de legitimá-lo. No Estado Constitucional burguês, tal papel é desempenhado, em primeira linha, pelos direitos fundamentais e pelo princípio da soberania do povo...” E conclui: "neles se incorporam as estruturas da consciência moral pós-convencional" (HABERMAS, 2012, p. 322). Nas sociedades pós-convencionais, a eticidade tradicional se fragmenta em questões éticas e morais, passando-se a exigir a aplicação de princípios gerais nas relações privadas e a obediência a um direito positivo na esfera profissional. É clara a assertiva de Habermas:

$\mathrm{E}$, quanto mais se aprofunda a generalização dos valores e dos motivos, tanto mais o agir comunicativo se desprende dos padrões de comportamento concretos e veiculados pela tradição. Tal desligamento faz com que o fardo da integração social seja tirado paulatinamente do consenso ancorado na religião e passado para processos de formação do consenso no interior da linguagem. (HABERMAS, 2012, p. 325).

Habermas (1990), em Para a Reconstrução do Materialismo Histórico, refere-se a um sétimo estágio que não foi desenvolvido por Kohlberg e que pressupõe uma ética universal da linguagem. O princípio de que justifica as normas não é mais um principio monologicamente aplicado, mas decorrente de um procedimento discursivo com vistas à universalização das mesmas.

É imperioso explicitar que, para Habermas (2003a), a autonomia do sujeito humano individual está conectada com o reconhecimento intersubjetivo em processos discursivos sobre a justiça moral de seus julgamentos e ações; mas o sujeito alcança a individuação como ser 
diferenciado dos demais por meio do reconhecimento discursivo de aspectos singulares de sua identidade. Nesse ponto, é necessário elucidar que a concepção habermasiana de autonomia é concebida como o aspecto moral da liberdade, enquanto autorrealização constitui a sua dimensão ética ${ }^{8}$, estabelecendo ainda uma distinção entre autonomia pessoal e autonomia moral. De um lado, a autonomia pessoal relaciona-se à prerrogativa individual de eleição dos projetos pessoais de vida; de outro lado, a autonomia moral conecta-se a princípios moralmente vinculantes delineados pelo Princípio $\mathrm{U}^{9}$, à luz da ética do discurso. A concepção kantiana de autonomia moral é interpretada habermasianamente em uma perspectiva dialógica e intersubjetiva, porquanto o indivíduo se torna autônomo, à medida que se insere em processos discursivos de reflexão crítica nos quais são problematizadas suas pretensões de validade. Nesse sentido, é oportuno sublinhar o posicionamento de uma das principais comentadoras do empreendimento habermasiano, Maeve Cooke (1992), professora da School of Philosophy, na Irlanda, relativamente à distinção entre discursos éticos e morais:

Para Habermas discursos éticos (pós convencionais), como discursos morais são guiados pela suposição ideal de que nenhum argumento é excluído em princípio da avaliação crítica no diálogo, bem como de que nenhuma pessoa capaz de falar e agir poderia ser excluída do diálogo, assim como ninguém deve ser impedido de introduzir novos argumentos, de questionar qualquer afirmação, de expressar suas necessidades, desejos, etc., e de que se uma norma ou princípio é moralmente válido, todos os participantes em um discurso moral teriam que concordar que ele é válido para todos. (COOKE, 1994, p. 90).

A autonomia representa, portanto, a dimensão moral do desenvolvimento da subjetividade. Como leciona a autora, "o self pósconvencional ganha autonomia na medida em que seus julgamentos e ações sejam aceitos como válidos para todos pelos participantes em um discurso moral." (COOKE, 1994, p. 90). Tal papel constitutivo do discurso que concebe a autonomia em seu aspecto moral está intimamente relacionada à concepção de "comunidade de comunicação universal". Pondera Habermas 
que a comunidade ilimitada de comunicação constitui uma "suposição idealizadora de uma forma de vida universalista, onde cada um pode assumir a perspectiva de cada um dos outros e onde cada um pode contar com o reconhecimento recíproco por parte de todos." (HABERMAS, 2002b, p. 220).

Em síntese, a projeção da comunidade universal configura uma suposição ideal decorrente da própria estrutura linguística, permitindo ao indivíduo, não um desengajamento, mas uma inserção em uma comunidade projetada. A autonomia é concebida como autonomia moral, porque as ações individuais "devem ser consideradas como moralmente justas por todos os membros de uma comunidade universal." (COOKE, 1992, p. 274). Ressaltamos que a concepção de subjetividade, delineada por Habermas (2002b), representa uma releitura da distinção conceitual de George Herbert Mead (1980, apud Habermas, 2002b) em relação a dois aspectos fundamentais da identidade: o I e o Me. Delineia-se uma relação dialética na qual o I busca o reconhecimento de sua singularidade, enquanto o $\mathrm{Me}$ controla as expectativas libertárias do I. Não obstante, o self pósconvencional pressupõe que o I, enquanto fonte de impulsos libertários, rompe com os padrões legítimos de uma sociedade, simbolizados em uma dimensão convencional representada pelo Me; entretanto, em Habermas (2002b), a tensão entre o I e o Me é compreendida como uma relação entre autodeterminação e autorrealização.

Nesse cenário, o Me de Mead (1980, apud Habermas, 2002b) simboliza uma instância de controle, ou seja, a dimensão convencional do self que controla as expectativas autênticas do I; mas tal dialética moral é interpretada habermasianamente por meio de um self pós-convencional que pressupõe, como já mencionado, não um desengajamento, mas inserção em uma comunidade projetada.

De fato, se em sociedades pós-convencionais o sujeito moralmente autônomo supõe o reconhecimento de suas ações em uma perspectiva ideal por meio de uma integração projetada, que transcende os padrões considerados legítimos de uma sociedade, torna-se claro que não seria possível falar em uma tentativa de conciliação entre o $I$ e $\mathrm{o} \quad \mathrm{Me}$ 
(convencional), porquanto o I projeta um novo $M e$, que corresponde a uma nova dimensão intersubjetiva de "condições de comunicação de um discurso universal". Leciona Cooke, acerca da perspectiva habermasiana, que "a pessoa autônoma é aquela que age moralmente e que julga moralmente, tal como uma pessoa deve esperar que uma comunidade de comunicação universal reconheça suas ações e julgamentos como moralmente justos." (COOKE, 1992, p. 273). Desse modo, a perspectiva habermasiana supõe que discursos morais se configuram por meio da suposição ideal, segundo a qual nenhum argumento, em princípio, é imune a processos dialógicos de reflexão crítica. O herdeiro da Escola de Frankfurt, em passagem elucidativa, leciona que:

No agir comunicativo as suposições de autodeterminação e de autorrealização mantêm um sentido rigorosamente intersubjetivo: quem julga e age moralmente tem de poder esperar o assentimento de uma comunidade de comunicação ilimitada e quem realiza uma história de vida assumida responsavelmente tem de poder esperar o reconhecimento dessa mesma comunidade. De acordo com isso, a minha identidade própria, ou seja, minha autocompreensão como um ser individuado que age autonomamente, só pode estabilizar-se se eu for reconhecido como esta pessoa. (HABERMAS, 2002, p. 226).

Sob essa ótica, para Habermas (2003a), o desenvolvimento da capacidade individual de julgamento moral pressupõe os três níveis e seis estágios de desenvolvimento da competência moral, sendo que, no nível pósconvencional, alcança-se a possibilidade do exercício crítico da razão. Em Taylor (1985), diferentemente, a racionalidade do indivíduo autointerpretativo é substantiva, e não procedimental, pressupondo a articulação dos bens e valores conectados às práticas culturais de uma comunidade. Assim, para Taylor (1985), em contraposição à perspectiva habermasiana, um julgamento ético é considerado como válido somente para aqueles que compartilham um universo substantivo inerente a uma forma de vida específica. 
ENTRE DIVERSIDADE PROFUNDA E PATRIOTISMO CONSTITUCIONAL [...]

Diante dessa estrutura conceitual, pressupõe um self convencional, incapaz de distanciar-se criticamente dos padrões legítimos de uma sociedade. Habermas (2012), por sua vez, leciona que o self pósconvencional possui capacidades cognitivas que lhe permitem distanciar-se de suas contingências culturais singulares.

\section{Considerações Finais}

Entendemos que o modelo de identidade desenvolvido por Taylor, paradoxalmente, tende a negar seus próprios pressupostos dialógicos de construção da identidade, valorizando o monologismo, ao minimizar o intercâmbio cultural. Tal perspectiva resulta de uma interpretação particular de Taylor, que estabelece erroneamente uma conexão necessária entre ideal da autenticidade e política da diferença, revelando uma certa ambiguidade em seu empreendimento teórico. De um lado, afirma que a construção da identidade constitui um processo aberto, mediado linguisticamente, pelo qual rearticulamos nossas singularidades; de outro, pretende preservar os laços culturais que definem nossa identidade autêntica. Ao vincular a subjetividade individual a uma comunidade linguística, Taylor termina por negar o próprio potencial crítico das identidades e o diálogo cultural. Diante do exposto, enfatizamos a importância da compreensão habermasiana que estimula o exercício crítico da razão por meio de uma relação reflexiva relativamente a nossas contingências culturais e históricas.

Diante do exposto, compreendemos que a concepção tayloriana de self contém recursos teóricos valiosos para a promoção da pluralidade, mas percebemos uma ambiguidade evidente no seu arcabouço teórico, pois tal compreensão confronta com a perspectiva desenvolvida na política de reconhecimento que estimula a reificação identitária. Como assinalamos, o filósofo afirma a existência de uma multiplicidade de fontes morais que constituem a identidade moderna, contrapondo-se a concepções rígidas de um self descentrado típico da tradição cartesiana. Ao rejeitar também um self unitário, sua perspectiva é aberta a uma multiplicidade de fontes morais, revelando o caráter complexo e multifacetado da identidade. 
Outrossim, a percepção relativa à natureza dialógica do self e a ênfase na pluralidade de fontes morais constituem um instrumental teórico importante para combater essencializações identitárias; mas tal potencialidade é enfraquecida no seu relato acerca da política da diferença, que termina por promover a incomunicabilidade e a intolerância.

\title{
BETWEEN DEEP DIVERSITY AND CONSTITUCIONAL PATRIOTISM: A DIALOGUE BETWEEN HABERMAS AND TAYLOR
}

\begin{abstract}
In the discussion about multiculturalism, political theoreticians criticize the liberal conception of citizenship. The theoretic perspective of Charles Taylor, who developed a politics of difference capable of addressing the pretensions of historically discriminated groups, stands out in this context. Jürgen Habermas, one of the most brilliant philosophers of the second generation of the School of Frankfurt, in his turn outlined a proceduralist perspective concerning the political philosophy of recognition that was markedly opposed to the philosophical perspective developed by Charles Taylor, in view of its post-conventional model of the self. This article attempts to clarify the debate through the theoretical contraposition between the idea of deep diversity delineated by Taylor and the conception of constitutional patriotism developed by Jürgen Habermas. I defend the thesis according to which the model of constitutional patriotism constitutes a sophisticated model of integration of difference capable of addressing the challenges of multicultural societies.
\end{abstract}

Keywords: Taylor. Habermas. Multiculturalism. Constitutional patriotism. Recognition.

\section{Notas explicativas}

${ }^{1}$ Em Kant (1964), a legislação moral não admite que uma ação possa ser cumprida segundo uma inclinação ou um interesse, mas somente para obedecer à lei do dever, ou seja, a ação moral não é determinada por desejos particulares, mas unicamente pelo princípio da vontade. Na perspectiva tayloriana, Kant, ao definir a moral de acordo com o imperativo categórico, termina por negligenciar aspectos fundamentais relativos à felicidade e ao conteúdo emocional das ações humanas. Nesse sentido, Ruth Abbey, uma das principais comentadoras do empreendimento tayloriano, assinala: "A filosofia moral moderna fornece respostas tipicamente universalistas às questões sobre o que é certo fazer para e pelos outros. Tais respostas são estabelecidas como premissas de um ideal de igualdade humana. No entanto, Taylor encara a abordagem das respostas universalistas como tendendo a negligenciar as questões sobre o que é bom ser, pois estas são suscetíveis de ter 
respostas mais pessoais e particulares." (ABBEY, 2000, p. 11); Para uma abordagem crítica a respeito da filosofia tayloriana, cf.: TULLY, 1994; REDHEAD, 2002.

2 Sobre essa questão, Antônio Cavalcanti Maia analisa: "As referências iniciais ao conceito de "patriotismo constitucional" (Verfassungspatriotismus) aparecem nos trabalhos de Habermas durante a metade da década de oitenta em uma das intervenções mais incisivas na esfera pública alemã: o Debate dos Historiadores - o Historikerstreit. Naquele momento, inserido na controvérsia acerca da tentativa de alguns historiadores alemães de negarem a singularidade do Holocausto, o herdeiro da Escola de Frankfurt - dirigindo a sua crítica a um grupo de historiadores conservadores liderados por Ernst Nolte (seguido por Hillgruber e Stürmer), que procurava trivializar o significado do passado nazista para a história alemã através de uma reinterpretação histórica - utilizou o conceito de "patriotismo constitucional”, cunhado pelo cientista político Dolf Sternberger." (MAIA, 2005, p. 133).

3 Segundo Cronin, as intervenções de Habermas no debate social e político alemão fornecem um valioso exemplo a respeito do que o patriotismo constitucional significou na prática: "Em resposta às alegações dos neoconservadores de que uma identidade nacional integral era indispensável para $o$ funcionamento da democracia, Habermas abraçou a idéia do patriotismo constitucional. Particularmente importantes para nossas preocupações são os argumentos nos quais ele se baseou para fundamentar essa idéia, abordando as questões relativas a qual responsabilidade os alemães deveriam continuar a aceitar pelas atrocidades nazistas e de como a orientação do pós-guerra da República Federal Alemã deveria ser compreendida." ( CRONIN, 2003, p. 17).

4 A respeito do debate Taylor-Habermas, cf.: FOSSUM, 2001; BAUMEISTER, 2003, p. 740-758; COOKE, 1997, p. 258-288; HABERMAS, 2002a, p. 229-267.

5 Como salienta Marcelo Cattoni, Habermas pretende mostrar que "a noção de patriotismo constitucional é, portanto, compativel com uma sociedade pluralista do ponto de vista cultural e político: por meio da construção de uma identidade constitucional comum, é possível articular a unidade da cultura política no contexto múltiplo de subculturas e formas de vida presentes na sociedade, desde uma perspectiva não fundamentalista." (CATTONI, 2006, p. 70).

${ }^{6}$ Nesse sentido, a fim de elucidar a centralidade da dimensão linguística no projeto habermasiano, no que se refere à construção dos vínculos identitários, assinala Maeve Cooke: "Tradições culturais seriam reproduzidas por meio de processos de avaliação intersubjetiva de pretensões de validade, onde as ordens legitimas seriam dependentes de práticas argumentativas abertas e críticas para estabelecer e justificar normas, e onde identidades individuais seriam auto-reguladas por meio de processos de reflexão crítica. (COOKE, 1994, p. 162).

7 Em seu artigo, John Erik Fossum (2001) examina a situação canadense por meio da análise de dois modelos contrastantes: a concepção de Taylor de diversidade profunda e a concepção de Habermas de patriotismo constitucional. De acordo com Fossum, a Carta Canadense promove um patriotismo constitucional, baseado em direitos que confronta com o ideal da diversidade profunda, delineado por Charles Taylor, requerido pela "realização dos objetivos coletivos da província de Québec, em relação à sobrevivência lingüística e cultural." De acordo com o ideal da

R. Fac. Dir. UFG, V. 37, n. 02, p. 13 - 40, jul. / dez. $2013 \quad$ ISSN 0101 - 7187 
diversidade profunda, a identidade é concebida como autenticidade - uma identidade que é particularmente minha - como a base da preocupação moderna pelo reconhecimento. A concepção de diversidade profunda, portanto, está associada com o ideal da autenticidade, segundo o qual cada indivíduo possui uma identidade única, uma forma original de ser humano que deve ser reconhecida e promovida. Destaca Fossum, que "a solução proposta por Taylor, em relação ao papel e status de Québec no Canadá, por exemplo, se baseia na diversidade profunda, através do reconhecimento constitucional da distintividade quebequense." Nesse sentido, segundo o autor, "os quebequenses concebem o Canadá em termos dualísticos, porque Québec é vista como uma nação distinta ou uma Comunidade Nacional e como uma das duas nações fundadoras da Confederação Canadense. "Leciona Fossum que os quebequenses separatistas se opõem à Carta Canadense, argumentando que "esta não promove um patriotismo constitucional viável; em primeiro lugar, porque a Carta Canadense foi introduzida sem o consentimento explícito da província de Québec. Em segundo lugar, a Carta é vista como desnecessária em Québec, pois desde 1975 Guebec adotou sua própria Carta de Direitos Humanos e Liberdades. Em terceiro lugar, a Carta Canadense não oferece proteções explícitas em relação à distintividade nacional ou cultural quebequense. $\mathrm{O}$ fundamento de direitos individuais previstos na Carta, portanto, são vistos como um impedimento a medidas efetivas em Québec para proteger e promover sua distintividade cultural e lingüística." Segundo Fossum, a Carta Quebequense oferece maiores proteções aos direitos da língua francesa e aos objetivos coletivos quebequenses do que a Carta Canadense. Esta, por sua vez, é mais capaz de conduzir a um patriotismo constitucional habermasiano, em razão da ênfase em direitos individuais e de sua orientação cosmopolita. (FOSSUM, 2001, p. 179-202).

8 Maeve Cooke, uma das principais comentadores do empreeendimento habermasiano, esclarece que a concepção habermasiana de subjetividade não é completamente exata. Em alguns momento Habermas formula a noção de autonomia como "autodeterminação" e "autorrealização". Em outros momento, utiliza a ideia de "individuação" em contraposição a "autorrealização": "Embora a noção de auto-determinação seja um sinônimo mal compreendido de autonomia como concebido por Habermas, e embora autorrealização não seja equivalente evidentemente a individuação, Habermas parece usar esses termos de forma alternada. Eu irei omitir a questão de se seria legítimo se referir a autonomia e autorrealização como dois aspectos relevantes da individuação. Nós deveríamos notar que autonomia e autorrealização são duas categorias que constituem o conceito de Habermas sobre liberdade individual, pois embora ele às vezes use os termos "liberdade", "autodeterminação"ou "autonomia"de forma alternada, ele freqüentemente esclarece que autonomia é o aspecto moral da liberdade, enquanto auto-realização é o aspecto ético ou estético.” ( COOKE, 1992, p. 272-273).

9 O Princípio U é formulado por Habermas da seguinte maneira: "toda norma válida deve satisfazer a condição de que as conseqüências e efeitos colaterais, que (previsivelmente) resultarem para a satisfação dos interesses de cada um dos indivíduos do fato de ser ela universalmente seguida, possam ser aceitos por todos os concernidos." (HABERMAS, 2003a p. 86). 


\section{Referências}

ABBEY, Ruth. Charles Taylor. Princeton: Princeton University Press, 2000.

BAUMEISTER, Andrea. Habermas: Discourse and Diversity. Political Studies, vol. 51, n. 4. Oxford: Blackwell Publishing, 2003, p. 740-758;

CATTONI, Marcelo. Poder Constituinte e Patriotismo Constitucional. Belo Horizonte: Mandamentos, 2006.

CITTADINO, Gisele. Pluralismo, Direito e Justiça Distributiva. Rio de Janeiro: Lumen Juris, 2000.

COOKE, Maeve. Authenticity and Autonomy. Taylor, Habermas and the Politics of Recognition". Political Theory, vol. 25, n. 5. London: Sage Publications, 1997, p. 258-288.

- Realizing the Post-conventional self. Philosophy and Social Criticism, vol. 20, n. 87. London: Sage Publications, p. 87-101.

CRONIN, Ciaran. Democracy and collective identity: In Defence of Constitutional Patriotism. European Journal of Philosophy, vol. 11, n. 1. London: Blackwell Publishing, 2003, p. 1-28.

FLEMING, Marie. Emancipation and Illusion. Rationality and Gender in Habermas's Theory of Modernity. Philadelphia: Pennsylvania State University Press, 1997.

FOSSUM, John Erik. Deep diversity versus constitutional patriotism. Taylor, Habermas and the Canadian constitutional crisis. Ethnicities, vol. 1, n. 2. London: Sage Publications, 2001, p. 179-206;

. The European Union in Search of an Identity. European Journal of Political Theory, vol. 2, n. 3. London: Sage Publications, 319-340.

FRASER, Nancy. What's Critical about Critical Theory?. In: MEEHAN, Johann (ed.). Feminist Read Habermas: Gendering the Subject of Discourse. New York: Routledge, 1995. p. 21-57.

HABERMAS, Jürgen. Para a Reconstrução do Materialismo Histórico. Trad. Carlos Nelson Coutinho. 2.ed. São Paulo: Brasiliense, 1990.

. The New Conservatism: Cultural Criticism and the

Historian's Debate. Cambridge, Massachusetts: MIT Press, 1994. 
A Reply. In: HONNETH, A; JOAS, H (eds.). Communicative Action: Essays on Jürgen Habermas's the Theory of Communicative Action. Trans. J. Gaines and D. L. Jones. Cambridge: Mit Press, 1998a.

Tecnos, 1998b. Identidades Nacionales y Postnacionales. Madrid:

A Inclusão do Outro Estudos de Teoria Política. Trad. George Sperber. São Paulo: Loyola, 2002a.

- Individuação através de socialização. Sobre a teoria da subjetividade de George Herbert Mead. In: Pensamento Pós-Metafísico. Trad. Flávio Beno Siebeneichler. 2.ed. Rio de Janeiro: Tempo Brasileiro, $2002 b$.

Consciência Moral e Agir Comunicativo. Trad. de Guido Antonio de Almeida. 2. ed. Rio de Janeiro: Tempo Brasileiro, 2003a.

Direito e Democracia- entre Facticidade e Validade, Tomos I e II. Trad. Flávio Beno Siebeneichler. 2. ed. Rio de Janeiro: Tempo Brasileiro, 2003b.

- Teoria do Agir Comunicativo - sobre a critica da

razão funcionalista. Tomo II. Trad. Flávio Beno Siebeneichler. 1.ed. São Paulo: Martins Fontes, 2012.

KANT. Immanuel. Fundamentação da Metafísica dos Costumes. Trad. Antonio Pinto de Carvalho. Lisboa: Companhia Editora Nacional, 1964.

LACROIX, Justine. For a European Constitutional Patriotism. Political Studies, vol. 50, n. 5. Oxford: Blackwell, 2002, p. 944-958.

MAIA, Antonio Cavalcanti. Diversidade Cultural, Identidade Nacional Brasileira e Patriotismo Constitucional. In: LOPES, Antonio Herculano e CALABRE, Lia. Identidade Cultural Brasileira. Rio de Janeiro: Casa de Rui Barbosa, 2005.

MEEHAN, Johanna. "Feminism and Habermas's Discourse Ethics". In: Philosophy \& Social Critiscism, vol. 26, n. 3. London: Sage Publications, 2000, p. 39-52.

REDHEAD, Mark. Charles Taylor. Thinking and Living Deep Diversity. Boston: Rowman \& Littlefield Publishers, 2002.

ROSALES, José Maria. Sobre la idea de patriotismo constitucional. In: CARRACEDO, José Rubio; ROSALES, José Maria; MÉNDEZ, Manuel 
Toscano. Ciudadania, Nacionalismo y Derechos Humanos. Madrid: Trotta, 2000.

SAURETTE, Paul. Questioning Political Theory. Charles Taylor's Contrarianism. Political Theory, vol. 32, n. 5, 2004, p. 723-733.

REDHEAD, Mark. Charles Taylor.Thinking and Living Deep Diversity. Boston: Rowman \& Littlefield Publishers, 2002.

SHABANI, Omid Payrow. Who's Afraid of Constitutional Patriotism? The Binding Source of Citizenship in Constitutional States. Social Theory and Practice, vol 28, n.3. Florida: Florida State University, 2002.

TAYLOR, Charles. A Política do Reconhecimento. In: TAYLOR, Charles. Argumentos Filosóficos. São Paulo: Loyola, 2000.

Self-interpreting animals. In: Human Agency and Language. Philosophical Papers I. Cambridge: Cambridge University Press, 1985.

TULLY, James. Philosophy in an Age of Pluralism - the Philosophy of Charles Taylor in question. Cambridge: Cambridge University Press, 1994.

Artigo submetido para avaliação em 20 de agosto de 2013 e aceito para publicação em 27 de novembro de 2013. 